\title{
The Effects of Phosphatidylserine (PS) Expression on HL 60, and the Efficacy of the Role of Doxorubicin (DOX) on HL60
}

\author{
Mohammad Alshugeer*, Hesham H Ameen and Abdullah Alhassoon \\ Ministry of Health, KSA \\ *Corresponding author: Mohammad Alshugeer, Ministry of health, Riyadh, KSA. \\ To Cite This Article: Mohammad Alshugeer. The Effects of Phosphatidylserine (PS) Expression on HL 60, and the Efficacy of the Role of \\ Doxorubicin (DOX) on HL60. Am J Biomed Sci \& Res. 2019 - 3(3). AJBSR.MS.ID.000668. DOI: 10.34297/AJBSR.2019.03.000668
}

Received: May 25, 2019 | Published: June 10, 2019

\begin{abstract}
Introduction: In recent studies the importance has been shown of the interactions between CD47 expressed on HL60 cells and the inhibitory Protein Kinase C (PKC) (Bisindolylmaleimide I).

Study objectives: the study aimed to explore the function of CD47 expressed on HL60 cells and the inhibitory Protein Kinase C (PKC).

Methodology: Initially, the expression of Phosphatidylserine (PS) levels in HL60 was analysed. The effect of PS expression on tumour cell growth and programmed cell death was also examined by triggering with BRIC-126 antibody. At the same time, we were able to observe the efficacy of doxorubicin (DOX) on HL60 when combined with other established leukemic drugs. The HL60 cell lines were analysed using flow cytometry to find out how PKC (Bisindolylmaleimide I) was expressed in HL60 and whether that expression was dependent on whether PKC is activated or inhibited. Although the efficacy of DOX on HL60 was clearly demonstrated by the research the mechanism through which it works was not clearly demonstrated.
\end{abstract}

Study Findings: There was an agreement with the view that PKC may have an anti-leukemic affect, and that it may potentially be a therapeutic target in neoplastic cells, although this would require further research specific to those areas. The data collected also tended to agree with the view that DOX could be a useful treatment for some malignant diseases.

Conclusion: The results of the present study showed the potential of using PKC as anti-leukemic therapeutic option.

Keywords: PKC; Malignant disease; Doxorubicin; CD47; HL60; Phosphatidylserine; Flow cytometry

\section{Introduction}

Phagocytosis, which entails removal of dying, damaged or altered cells, is an essential mechanism for haemostasis. The clearance of aged cells is characterized by a conformational change in Cluster of Differentiation 47 (CD47) due to autoantibody binding to Band 3, and appearance of phosphatidylserine (PS) on the outer leaflet of the cell membrane [1-3]. CD47, also known as integrin-associated protein (IAP), is a transmembrane protein of the immunoglobulin (Ig) superfamily, which is heavily glycosylated and expressed by all cells in the body [3]. CD47 controls immune responses, cell spreading and adhesion by binding to thrombospondin-1 (TSP1) [4] and communicates with transmembrane signal-regulatory

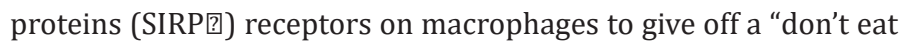
me" signal which plays a critical role in cellular processes, including apoptosis, proliferation, adhesion and migration $[5,6]$.
Cancer cells evade phagocytic elimination by cell surface up-regulation of phagocyte-inhibitory signals, such as CD47 [3]. Overexpression of CD47 promotes survival of the neoplastic cells in solid and haematological malignancies [7-9]. Blockade of CD47-SIRP? interaction enhances phagocytic elimination of CD47 over-expressing tumour cells [7,10]. Recent studies have shown that ligation of CD47 with monoclonal antibodies (mAbs) and the specific CD47-binding peptide 41NK, derived from TSP1 , can induce caspase-independent cell death characterized by cytoskeleton remodelling and phosphatidylserine (PS) expression on the cell surface [11-13].

Externalisation of phosphatidylserine (PS) to the outer membrane, another hallmark of apoptosis and phagocytosis, 
occurs as a result of reduced amino phospholipid translocase activity and activation of a calcium-dependent scramblase [14,15]. In the early stages of apoptosis, inhibition of translocase, in part due to an elevation in intracellular $\mathrm{Ca} 2+$ and activation of a lipid scramblase, allows the appearance of PS on the surface of the cells [16]. There are a number of PS-binding proteins that can act as a bridge between apoptotic cells and phagocytes such as plasmaprotein $\beta 2$-glycoprotein I, the product of growth arrest-specific gene 6 (Gas6) that binds to the Mer kinase and the protein milkfat globule epidermal growth factor 8 that bridge with vitronectin receptor integrin $(\alpha v \beta 3)$ and protein $S$ that binds PS $[17,18]$.

The protein kinase C (PKC), a ubiquitous cellular enzyme, is a family of homologous serine/threonine kinases [19]. There are at least 11 isoforms that are divided into three groups according to their second messenger requirements: classical, novel, and atypical [20]. PKC plays an important role in signal transduction in response to the production of diacylglycerol (DAG). PKC has also been associated with numerous physiological functions, including secretion and exocytosis, modulation of ion conductance, gene expression, and cell proliferation [21]. Activation of PKC has also been reported to be crucial to tumour growth. However, the bisindolylmaleimide derivatives of staurosporine are widely used as specific inhibitors of protein kinase $C$ (PKC) isoforms. Bisindolylmaleimide I (Bis I), the most commonly used PKC inhibitor, can block PKC activity by competitively inhibiting its ATP binding ability [22,23]. It also inhibits cAMP- and cGMP-dependent protein kinase [24].

A study by Gobbi et al. [25] showed that using PKC inhibitors as anti-cancer agents, particularly in acute myeloid leukaemia (AML), may be possible and requires further investigation. The HL60 (Human promyelocytic leukaemia cells) cell line has been used for laboratory research on how certain kinds of blood cells are formed. HL-60 cells proliferate continuously in suspension culture in nutrient medium supplemented with foetal bovine serum, L-glutamine, HEPES and antibiotic chemicals. The doubling time is about 36-48 hours. The cell line was derived from a 36-yearold woman with acute promyelocytic leukaemia. HL-60 cells are predominantly a neutrophilic promyelocyte [26].

The HL60 cultured cell line provides a continuous source of human cells for studying the molecular events of myeloid differentiation and the effects of physiologic, pharmacologic, and virologic elements on this process. HL60 cell model was used to study the effect of DNA topoisomerase (topo) II $\alpha$ and II $\beta$ on differentiation and apoptosis of cells [27]. Doxorubicin (DOX) is an anthracycline antibiotic used in treatment of various human neoplastic diseases including leukaemias, lymphomas, sarcomas, carcinomas and breast cancers [28]. It exerts its antitumor effects primarily via DNA intercalation and topoisomerase II inhibition thereby leading to apoptosis (Bao et al., 2012).

The observations, from Gobbi et al. [25] prompted the hypothesis that Bis I may play a role in CD47-mediated cell death. Herein, the author investigated the effect of Bis I on expression of phosphatidylserine (PS) following CD47-mediated cell death and cell surface expression of CD47 in HL60 acute promyelocytic cell line. These tests were carried out with and without the presence of DOX; this effectively also tests the efficacy of DOX in these situations.

\section{Study objectives}

The aim of this project is to provide supportive evidence of the effect of protein kinase C inhibitor (Bisindolylmaleimide I) on expression of Phosphatidylserine (PS).

\section{Materials and Methods}

\section{Cell culture}

HL60 cells were used throughout the experiment. The cells were cultured in RPMI 1640 medium supplemented with L-glutamate $(2 \mathrm{mM})$ and $10 \% \mathrm{FCS}$. Cells were maintained at $37^{\circ} \mathrm{C}$ in a humidified atmosphere with 5\% CO2-95\% air (NuAIRE Direct Heat Airflow). Cells were maintained between 1 x105 and 1x106 cells/mL in T25 culture flasks by sub-culturing twice. Cells (in RMP1 1640medium) were centrifuged at $300 \mathrm{~g}$ for five minutes before washing the cell pellet with $5 \mathrm{ml}$ of PBS. Next, the cell solution was centrifuged at $300 \mathrm{~g}$ for five minutes and the cells re-suspended in fresh culture media.

\section{Cell Count}

HL60 cells $(20 \mu \mathrm{l})$ were uniformly stained with $20 \mu \mathrm{l}$ of $0.4 \%$ (w/v) trypan blue (Sigma-Aldrich Poole, UK) and counted with a haemocytometer. Cell count was calculated using the formula:

Number of cells in single large square X2 (the dilution factor with trypan blue also x104cells/ml).

\section{Flow Cytometry}

Flow cytometry was carried out using a BD Accuri C6 flow cytometer (BD Biosciences, Oxford, UK) equipped with a digital laser. Approximately 10,000 cells were analysed from each treatment. Data analysis was performed using CFlow Plus software.

\section{Annexin-V FITC Binding Assay}

According to Pollard [29], testing the interaction between molecules is "one of the most common tests" in cellular and molecular biology. Assaying the level of interaction is always quantitative - it is never simply a yes or no answer. Thus, this assay will measure the quantity of cells that have been stained - these are the cells in which interaction has taken place.

With modifications of Jeremy et al. [13] methods, 1 x 106/ mL HL60 cells were washed twice with HBSS and reconstituted in HBSS. Cells were incubated in 96-well plates with $1 \mu$ l of Bisindolylmaleimide I (Bis I) (protein kinase inhibitor) for 30 minutes before incubating with $5 \mu$ l of BRIC-126 or BRIC-235 overnight at room temperature on an orbital shaker. Following incubation, cells were washed twice in HBSS followed by washing in 1xAnnexin V-FITC binding buffer and re-suspended in 1xAnnexin V-FITC binding buffer. Cells were then incubated with Annexin V-FITC $(5 \mu \mathrm{l})$ for 15 minutes in the dark at room temperature. Samples were transferred to eppendorf tubes containing 1xAnnexin V-FITC binding buffer $(300 \mu \mathrm{l})$ placed on ice, prior to staining with PI and flow cytometric data analysis for PS exposure. 


\section{Doxorubicin Assay}

Like the binding assay, this is a quantitative assessment of the number of cells affected in each sample; like the binding assay its accuracy and dependency are regarded as high, since the advice of other experts in the field was followed to ensure that this was the case, and to ensure there were no flaws in the design of the assay [29]. Enough suspension cells were recovered to complete assay; a stock of doxorubicin was diluted in RPMI culture media to produce different concentrations $(50-500 \mu \mathrm{M})$. The cells were washed with HBSS and diluted in RPMI culture media to a concentration of $7 \times 105 / \mathrm{ml}$. The cells were placed in a 24 -well plate $(1 \mathrm{ml}$ per well) and mixed with different concentrations $(50-500 \mu \mathrm{M})$ of doxorubicin before incubating them for up to 72 hours at $37 \mathrm{oC}$ in a humidified atmosphere with 5\% CO2-95\% air, with cells analysed at 0 hours, 24 hours, 48 hours and 72 hours after adding doxorubicin. After doxorubicin treatment, the cells were washed with HBSS and mixed with PBS before staining them with anti-human CD47-FITC $(5 \mu \mathrm{l})$ from BD Biosciences, Oxford, UK. Subsequently, the cells were incubated in the dark for 15 minutes at room temperature. After incubation, samples were transferred to eppendorf tubes containing
PBS $(300 \mu \mathrm{l})$ and placed on ice, followed by flow cytometric data analysis for surface expression of CD47.

\section{Results}

The effect of DOX on CD47 expression and the role of PKC in CD47-mediated PS exposure were investigated and the following results were obtained.

\section{Bisindolylmaleimide I enhance CD47-mediated cell death in HL60 cells}

To ascertain the role of bisindolylmaleimide I in externalization of PS to outer surface of HL60 cells (between 1x105 and $1 \times 106$ cells/ml concentration), HL60 cells were treated with $1 \mu \mathrm{l}$ of bisindolylmaleimide I, $5 \mu$ l of BRIC-126 or BRIC-235 overnight at $37 \mathrm{oC}$ in an orbital shaker and stained with annexin-V FITC $(5 \mu \mathrm{l})$. Controls (Figure 1A/B) were stained with only annexin-V and PI. Ligation of CD47 with BRIC-126 (Figure 1C) or BRIC 235 without bisindolylmaleimide (Figure 1E) triggered CD47-mediated cell death in HL60 cells, which became enhanced following treatment with bisindolylmaleimide I (Figure 1D \& 1F).
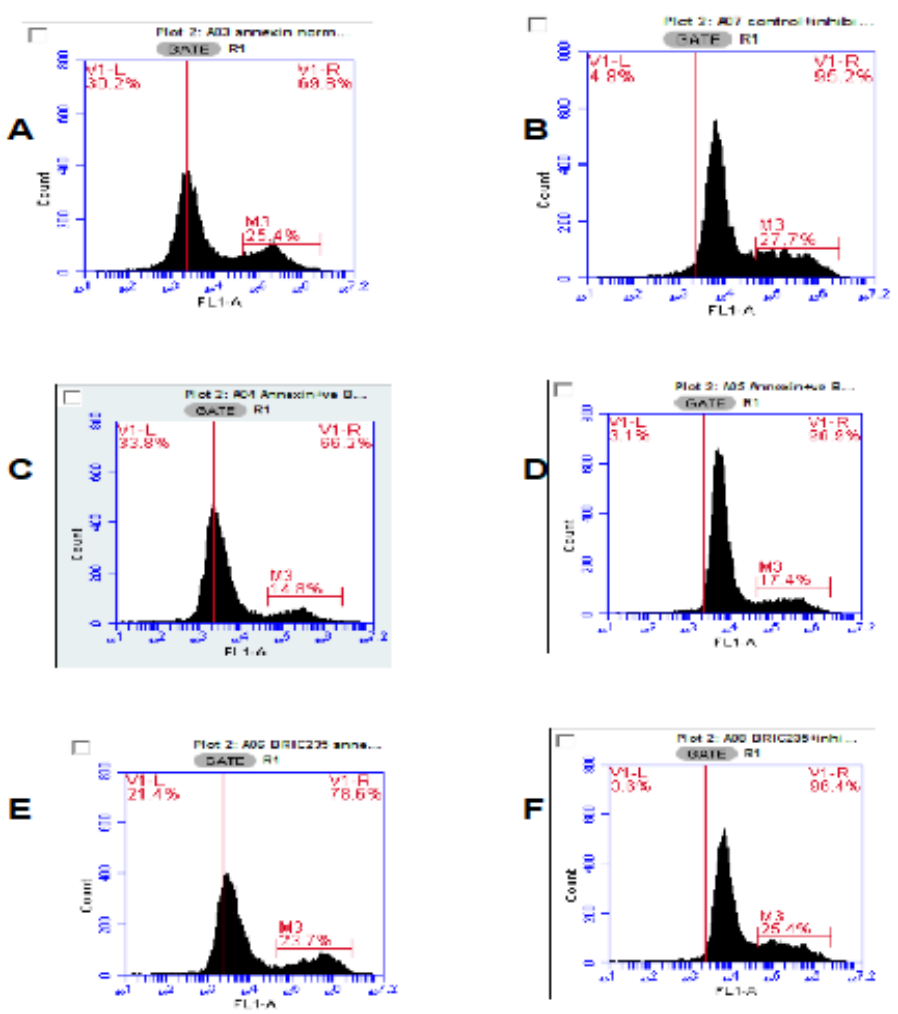

Figure 1: Bisindolylmaleimide I enhances CD47-mediated cell death in HL60 acute promyelocytic leukaemia cell line. HL60 cells ( 1 x 106/ml) were incubated overnight with monoclonal antibodies and bisindolylmaleimide I. Cell surface expression of PS was measured by flow cytometry following staining with annexin-V. Each experiment was repeated three times $(n=3)$.

\section{HL60 cells express increased surface CD47 with DOX}

HL60 cells were treated with increasing concentrations (50 to $500 \mu \mathrm{M}$ ) of doxorubicin and incubated for 72 hours. Following the procedure used by other researchers, the controls were left unstained, whilst the isotype controls were treated with anti-CD47 FITC. In comparison to the control, HL60 expressed an increased level of surface CD47 at all concentrations of doxorubicin after
0 hours, with highest CD47 expression at $50 \mu \mathrm{M}$. However, after 72 hours the control cells still expressed a high level of surface expression whilst treated cells expressed reduced surface CD47 expression. The relative percentage surface CD47 expression by HL60 cells following treatment with doxorubicin is shown in Figure $2 \& 3$. 

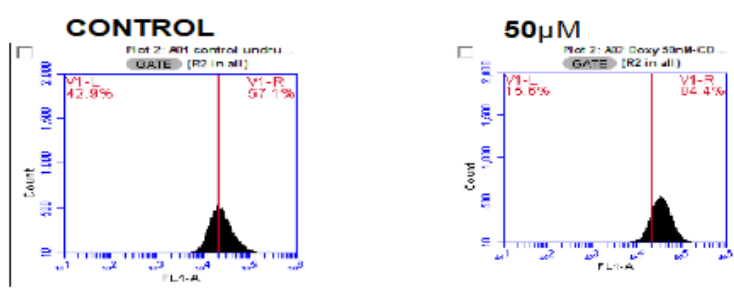

$100 \mu \mathrm{M}$

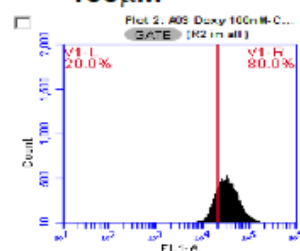

$250 \mu \mathrm{M}$

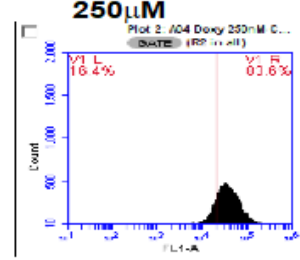

$500 \mu \mathrm{M}$
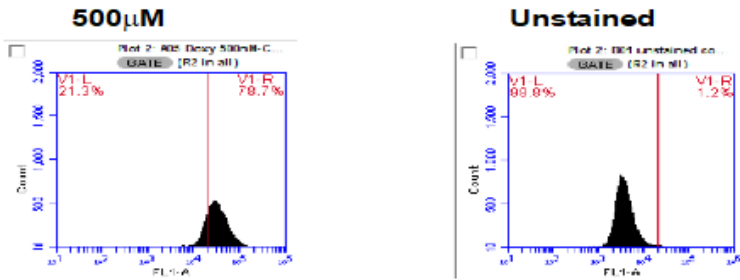

Figure 2: Doxorubicin causes an increase in expression of CD47 in HL60 cells. Here, representative plots of surface CD47 expression by flow cytometry immediately following treatment with increasing concentrations $(50 \mu \mathrm{M}$ to $500 \mu \mathrm{M})$ of doxorubicin at 0 hours are shown. Histograms show a shift in CD47 expression from control (untreated HL60 cells) after treatment with doxorubicin. Each experiment was repeated three times ( $n=3$ ).

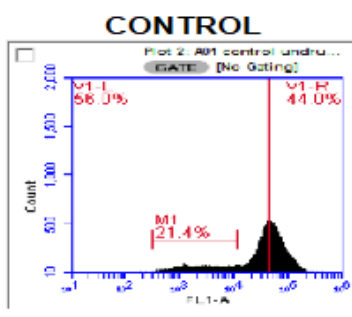

$100 \mu \mathrm{M}$

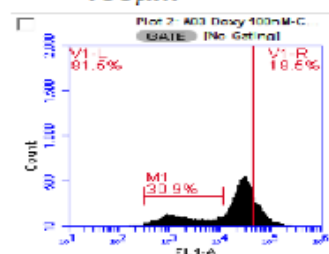

$500 \mu \mathrm{M}$

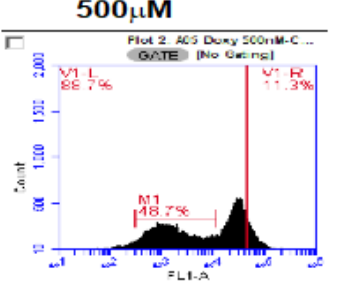

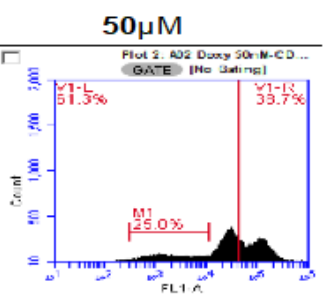

$250 \mu \mathrm{M}$

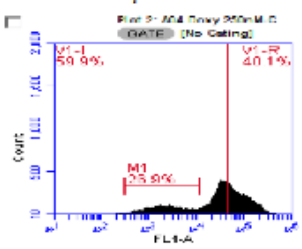

Unstained

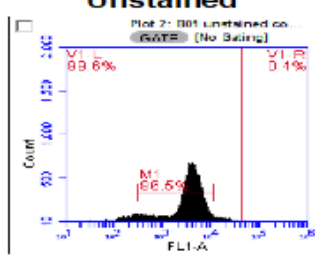

Figure 3: Doxorubicin causes a decrease in expression of CD47 in HL60 cells. Here, representative plots of surface CD47 expression by flow cytometry following treatment with increasing concentrations $(50 \mu \mathrm{M}$ to $500 \mu \mathrm{M})$ of doxorubicin after 24 hours are shown. Histograms show a reduce in CD47 expression from control (untreated HL60 cells) after treatment with doxorubicin. Each experiment was repeated three times ( $n=3$ ).

Figure 1 shows a series of histograms (A to F) showing fluorescence concentration in the samples whenincubated overnight. Figure $1 \mathrm{~A}$ represents HL-60 cells with bisindolylmaleimide I and Figure 1B represents HL-60 cells without bisindolylmaleimide I. Figure $1 \mathrm{C}$ is the histogram after overnight incubation of HL-60 cells with BRIC-126 and Figure 1D HL-60 cells with bisindolylmaleimide
I. The final pairs in the illustration are Figure 1E, HL-60 cells with BRIC-256 and Figure 1F, HL-60 cells with bisindolylmaleimide I. Each of these experiments was repeated three times to obtain mean or average figures. Figure 2 consists of six histograms following the flow cytometry. This set of figures was obtained immediately after introduction ( 0 Hours) and each histogram is labelled with the 
concentration. At this point, it appears that the introduction of DOX has actually induced an increase in the expression of CD47. This is not unexpected and is in line with previous findings.

Figure 3 reproduces Figure 2 but represents the same samples 24hours after introduction. Here it can immediately be seen that a reduction of CD47 expression has been induced, but it also clear that the fluorescence is occurring over a wider spectrum, so that although the peak is lower, the width is wider.

Figure 4 show the same samples 48 hours after introduction. When compared directly to Figure 3, it can be seen that there is a slight increase of expression of CD47, but that, once more the spectrum is wider.

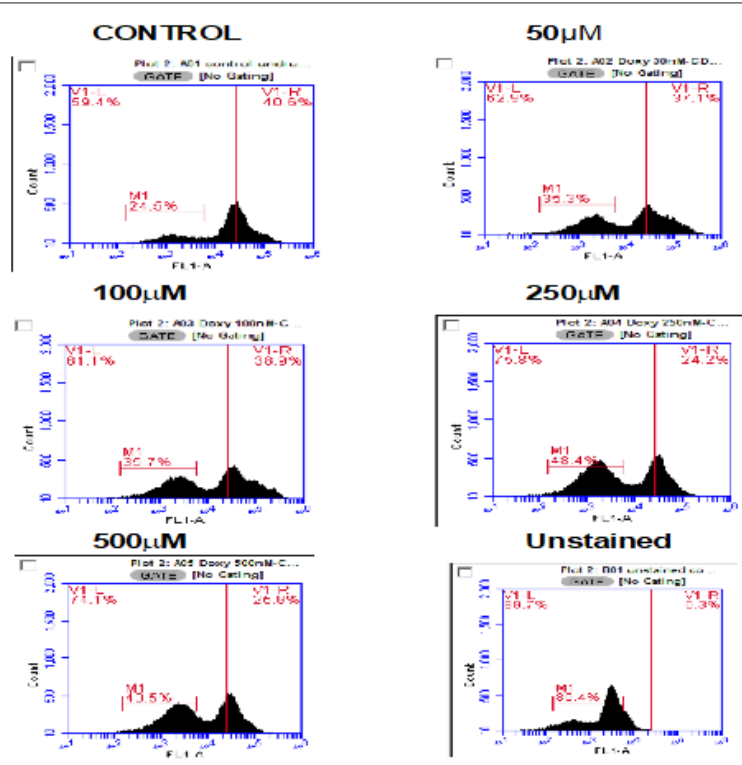

Figure 4: Doxorubicin causes a decrease in expression of CD47 in HL60 cells. Here, representative plots of surface CD47 expression by flow cytometry following treatment with increasing concentrations $(50 \mu \mathrm{M}$ to $500 \mu \mathrm{M})$ of doxorubicin after 48 hours are shown. Histograms show a decrease in CD47 expression from control (untreated HL60 cells) after treatment with doxorubicin. Each experiment was repeated three times $(n=3)$.
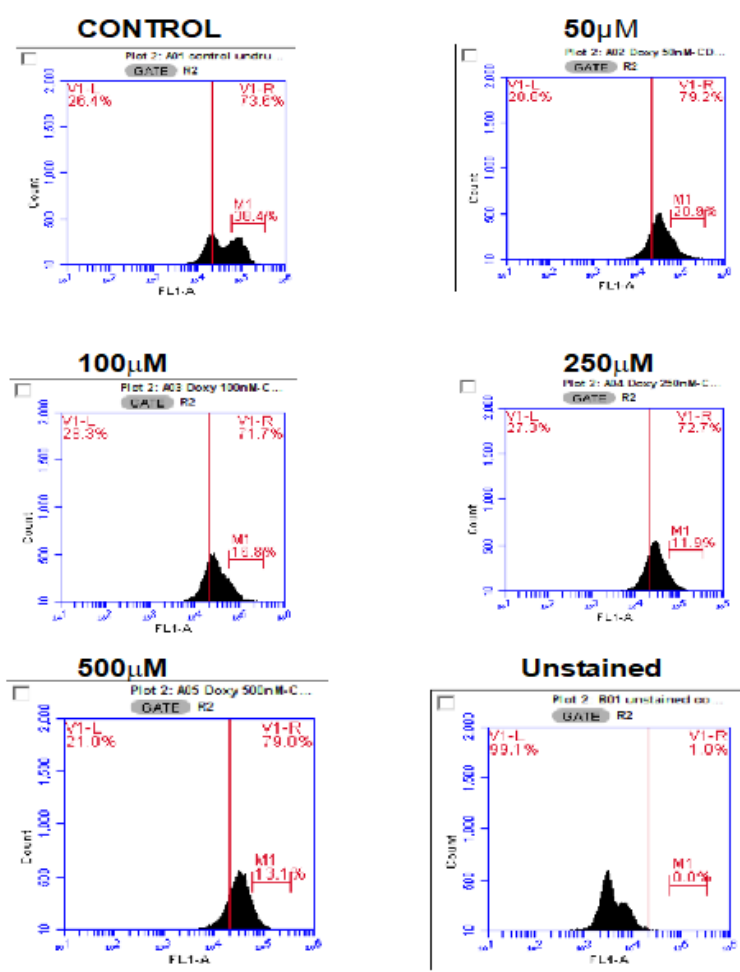

Figure 5: Expression of surface CD47 by HL60 cells reduced after 72hour incubation. Representative plots of surface CD47 expression by flow cytometry following treatment with increasing concentrations $(50 \mu \mathrm{M}$ to $100 \mu \mathrm{M})$ of doxorubicin after 72 hours are shown. Histograms show surface CD47 expression by HL60 cells reduced after 72-hour incubation with doxorubicin. Each experiment was repeated three times $(n=3)$. 
Finally, Figure 5 shows the samples after 72 hours. These figures also show a slight increase in expression of CD47, but spectrum width has returned to levels comparable with the 0hour samples.

\section{Discussion}

In this study, determination of PS exposure was measured to study the effect of Protein Kinase $\mathrm{C}$ inhibitor (Bisindolylmaleimide I). This aspect of PKC activity was explained in many studies (Versteeg et al., 2013; Wagner-Britz et al., 2013; Wood et al., 2013 amongst others) and it has important therapeutic implications since induction of mortality by terminal differentiation represents an alternative approach to cytodestruction of cancer cells by conventional antineoplastic agents, and is therefore important biologically. In this respect, Bisindolylmaleimide I is clearly seen in the structure of PKC [30] residue 574-turn motif, need to be phosphorylated towards a PKC-beta-specific inhibitor sitedirected mutagenesis of the compound for its full activation [31] and co-crystallized as an asymmetric pair which is mediated by 3-phosphoinositide-dependent protein kinase-1 [32].

However, while Bisindolylmaleimide I are currently evaluated in the treatment of the neoplastic cells, able to induce leukemic cells in other subtypes [33] In this work, it was attempted to find a biochemical explanation for the fact that DOX is active against HL60 cells, which are known for the presence of altered topoisomerase II. The presence of a formamidine group containing morpholine or hexamethyleneimine ring at the 3 ' position enhances the uptake of anthracycline drugs by HL60 cells. This effect is especially pronounced in the case of DOX. Therefore, it can be concluded that addition of a morpholine ring in formamidinoanthracyclines significantly enhances the ability of this drug to penetrate cell membranes. The reduced uptake of DOX by HL60 cells may explain why this drug was approximately two times less cytotoxic against this cell line when compared with HL60 cells. The effect of DOX and its derivatives on supercoiled DNA cleavage by topoisomerase II in a cell-free system indicated that contrary to the effect of DOX do not stabilize the cleavable complex of topoisomerase II with DNA. Thus, it may be concluded that topoisomerase II is not the primary target of DOX and that high cytotoxic activity of these compounds toward HL60 cell line is due to a mechanism of action, which is not related to DNA topoisomerase II inhibition.

Other research into the effects of CD47 on HL60 which is comparable with the results discussed above includes work by Head et al. [12]; Gonelli et al. (2009); Roberts et al. (2013) and Oldenborg [3]. Each of these researchers appears to have worked with a single concentration rather than the four concentrations of the experiments carried out for this research. However, despite this difference their findings appear to be largely in agreement with the results obtained here. While the PKC inhibitor peptide The PKC BIM1 complex interacts with the zinc finger of lambda/ iota PKC characterization of lambda-interacting protein (LIP) [34]. Lambda-interacting protein is a selective activator of lambda/iota PKC. Phosphorylation of a PKC induces a conformation leading to import of a PKC into the nucleus [35] the entire 587-amino acid coding region of a new PKC isoform, PKC iota [36]. The bound BIM1 inhibitor blocks the ATP-binding site and puts the kinase domain into an intermediate open conformation [37]. The value of such calculations lies in understanding a variant was designed which showed improved binding characteristics of configurationally stable atropisomeric bisindolylmaleimides [38].

In other research, it showed negligible effects of Bisindolylmaleimide induction of leukemic maturation, this does exclude that the association of PKC inhibitor might represent an important therapeutic combination. In this respect, it is also noteworthy that the PKC inhibitor was able to significantly modulate the degree of apoptosis induced in vivo. The resistance of leukemic cells to currently used therapies occurs in part because leukemic cells safeguard their survival through mechanisms that allow them to escape death receptor-mediated apoptosis [39]. Much attention has recently attracted the protein kinase inhibitor for its ability to overcome resistance to apoptosis in several tumors, including hematological malignancies [40].

While many studies have demonstrated that resistance in a variety of hematological malignancies is mainly due to constitutively level of CD47 and protein kinase C [40], it has demonstrated that also the selective activation of the PKC family member can markedly counteract the susceptibility to be cytotoxicity in the HL60 cell line. Current findings are in line with those recently described by [25], who demonstrated that PKC activation by phorbol esters confers resistance to apoptosis induction in the leukemic cell line. However, an important difference between the study of [25] and current data is that inhibitor which was used might have important future clinical applications. In fact, [41] have recently reviewed the potential use of PKC developed by important pharmaceutical companies, which specifically inhibit PKC and ameliorate pathological conditions in a rodent insulin resistance model.

Another experimenter who carried out a similar experiment with similar concentrations [42] also had results which were not hugely different, leading the researcher to comment that the results obtained seemed dependent on the type of cell being studies, but that the role of calpains in CD47-mediated cell death was heterogeneous [42], and that CD47 played a role in MDR development in HEL cells [43-52].

\section{Conclusions}

The results of the present study showed the potential of using PKC as anti-leukemic therapeutic option. Other studies are required to confirm our data.

\section{References}

1. Kay M M (1984) Localization of senescent cell antigen on band 3 . Proceedings of the National Academy of Sciences of the United States of America 81(18): 5753-5757.

2. Boas FE, Forman L, Beutler E (1998) Phosphatidylserine exposure and red cell viability in red cell aging and in hemolytic anemia. Proceedings of the National Academy of Sciences of the United States of America 95 (6): 3077-3081.

3. Oldenborg PA (2013) CD47: A Cell Surface Glycoprotein Which Regulates Multiple Functions of Hematopoietic Cells in Health and Disease. ISRN Hematology 2013: 614619.

4. Murata Y, Kotani T, Ohnishi H, Matozaki T (2014) The CD47-SIRPalpha signalling system: its physiological roles and therapeutic application. Journal of Biochemistry 155(6): 335-344. 
5. Oldenborg PA, Zheleznyak A, Fang YF, Lagenaur CF, Gresham HD, et al. (2000) Role of CD47 as a marker of self on red blood cells. Science 288(5473): 2051-2054.

6. Sick E, Jeanne A, Schneider C, Dedieu S, Takeda K, et al. (2012) CD47 update: a multifaceted actor in the tumour microenvironment of potential therapeutic interest. British Journal of Pharmacology 167(7): 1415-1430.

7. Chao MP, Alizadeh AA, Tang C, Myklebust JH, Varghese B, et al. (2010) Anti-CD47 antibody synergizes with rituximab to promote phagocytosis and eradicate non-Hodgkin lymphoma. Cell 142(5): 699-713.

8. Zhao XW, van Beek EM, Schornagel K, Van der Maaden H, Van Houdt $M$, et al. (2011) CD47-signal regulatory protein-alpha (SIRPalpha) interactions form a barrier for antibody-mediated tumor cell destruction. Proceedings of the National Academy of Sciences of the United States of America 108(45): 18342-18347.

9. Unanue ER (2013) Perspectives on anti-CD47 antibody treatment for experimental cancer. Proc Natl Acad Sci U S A 110(27): 10886-10887.

10. Kim D, Wang J, Willingham SB, Martin R, Wernig G, et al. (2012) AntiCD47 antibodies promote phagocytosis and inhibit the growth of human myeloma cells. Leukemia 26(12): 2538-2545.

11. Mateo V, Brown EJ, Biron G, Rubio M, Fischer A, et al. (2002). Mechanisms of CD47-induced caspase-independent cell death in normal and leukemic cells: link between phosphatidylserine exposure and cytoskeleton organization. Blood 100(8): 2882-2890.

12. Head DJ, Lee ZE, Swallah MM, Avent ND (2005) Ligation of CD47 mediates phosphatidylserine expression on erythrocytes and a concomitant loss of viability In Vitro. British Journal of Haematology 130(5): 788-790.

13. Jeremy KP, Plummer ZE, Head DJ, Madgett TE, Sanders KL, et al. (2009) 4.1R-deficient human red blood cells have altered phosphatidylserine exposure pathways and are deficient in CD44 and CD47 glycoproteins. Haematologica 94(10): 1354-1361.

14. Kamel N, Goubran F, Ramsis N, Ahmed AS (2010) Effects of storage time and leucocyte burden of packed and buffy-coat depleted red blood cell units on red cell storage lesion. Blood Transfusion 8(4): 260-266.

15. Segawa K, Kurata S, Yanagihashi Y, Brummelkamp TR, Matsuda F, et al. (2014). Caspase-mediated cleavage of phospholipid flippase for apoptotic phosphatidylserine exposure. Science 344(6188): 1164-1168.

16. Frasch SC, Henson PM, Kailey JM, Richter DA, Janes MS, et al. (2000) Regulation of phospholipid scramblase activity during apoptosis and cell activation by protein kinase Cdelta. The Journal of Biological Chemistry 275(30): 23065-23073.

17. Hanayama R, Tanaka M, Miwa K, Shinohara A, Iwamatsu A, et al. (2002) Identification of a factor that links apoptotic cells to phagocytes. Nature 417(6885): 182-187.

18. Anderson HA, Maylock CA, Williams JA, Paweletz CP, Shu H, et al. (2003) Serum-derived protein $S$ binds to phosphatidylserine and stimulates the phagocytosis of apoptotic cells. Nature Immunology 4(1): 87-91.

19. Steinberg SF (2008) Structural basis of protein kinase C isoform function. Physiological Reviews 88(4): 1341-1378.

20. Fan HC, Fernandez-Hernando C, Lai JH (2014) Protein kinase C isoforms in atherosclerosis: Pro- or anti-inflammatory? Biochemical Pharmacology 88 (2): 139-149.

21. Mischiati C, Melloni E, Corallini F, Milani D, Bergamini C, et al. (2008) Potential role of PKC inhibitors in the treatment of hematological malignancies. Current Pharmaceutical Design 14(21): 2075-2084.

22. Kim A, Bae YM, Kim J, Kim B, Ho WK, et al. (2004) Direct block by bisindolylmaleimide of the voltage-dependent $\mathrm{K}+$ currents of rat mesenteric arterial smooth muscle. European Journal of Pharmacology 483 (2-3): 117-126.

23. Park WS, Son YK, Ko EA, Ko JH, Lee HA, et al. (2005). The protein kinase C inhibitor, bisindolylmaleimide (I), inhibits voltage-dependent $\mathrm{K}+$ channels in coronary arterial smooth muscle cells. Life Sciences 77(5): 512-527.

24. Hers I, Tavare JM, Denton RM (1999) The protein kinase C inhibitors bisindolylmaleimide I (GF 109203x) and IX (Ro 31-8220) are potent inhibitors of glycogen synthase kinase-3 activity. FEBS Letters 460 (3): 433-436.

25. Gobbi G, Mirandola P, Carubbi C, Micheloni C, Malinverno C, et al. (2009) Phorbol ester-induced PKCepsilon down-modulation sensitizes AML cells to TRAIL-induced apoptosis and cell differentiation. Blood 113(13): 3080-3087.

26. Gallagher R, Collins S, Trujillo J, McCredie K, Ahearn M, et al. (1979) Characterization of the continuous, differentiating myeloid cell line (HL-60) from a patient with acute promyelocytic leukemia. Blood 54(3): 713-733.

27. Ratanachoo K, Gascoyne PR, Ruchirawat M (2002) Detection of cellular responses to toxicants by dielectrophoresis. Biochimica Et Biophysica Acta 1564(2): 449-458.

28. Roaten JB, Kazanietz MG, Caloca MJ, Bertics PJ, Lothstein L, et al. (2002) Interaction of the novel anthracycline antitumor agent $\mathrm{N}$-benzyladriamycin-14-valerate with the C1-regulatory domain of protein kinase C: structural requirements, isoform specificity, and correlation with drug cytotoxicity. Molecular Cancer Therapeutics 1(7): 483-492.

29. Pollard TD (2010) A Guide to Simple and Informative Binding Assays. Molecular Biology of the Cell 21(28): 4061-4067.

30. Baldwin RM, Parolin DA, Lorimer IA (2008) Regulation of glioblastoma cell invasion by PKC iota and RhoB. Oncogene 27(25): 3587-3595.

31. Bicaku E, Patel R, Acevedo Duncan M (2005) Cyclin-dependent kinase activating kinase/Cdk7 co-localizes with PKC-ı in human glioma cells. Tissue Cell 37(1): 53-58.

32. Busschots K, Lopez-Garcia LA, Lammi C, Stroba A, Zeuzem S, et al. (2012) Substrate-Selective Inhibition of Protein Kinase PDK1 by Small Compounds that Bind to the PIF-Pocket Allosteric Docking Site. Chemistry \& Biology 19(9): 1152-1163.

33. Matsumoto T, Hasegawa H, Onishi S, Ishizaki J, Suemori K, et al. (2013) Protein kinase $\mathrm{C}$ inhibitor generates stable human tolerogenic dendritic cells. Journal of Immunology 191(5): 2247-2257.

34. Messerschmidt A, Macieira S, Velarde M, Bädeker M, Benda C, et al. (2005) Crystal Structure of the Catalytic Domain of Human Atypical Protein Kinase C-iota Reveals Interaction Mode of Phosphorylation Site in Turn Motif. Journal of Molecular Biology 352(4): 918-931.

35. Cantin GT, Yi W, Lu B, Park SK, Xu T, et al. (2008). Combining protein-based IMAC, peptide-based IMAC, and MudPIT for efficient phosphoproteomic analysis. Journal of Proteome Research 7(3): 1346-1351.

36. White WO, Seibenhener ML, Wooten MW (2002) Phosphorylation of tyrosine 256 facilitates nuclear import of atypical protein kinase C. Journal of Cellular Biochemistry 85(1): 42-53.

37. Gassel M, Breitenlechner CB, König N, Huber R, Engh RA, et al. (2004) The protein kinase $C$ inhibitor bisindolyl maleimide 2 binds with reversed orientations to different conformations of protein kinase A. The Journal of Biological Chemistry 279(22): 23679-23690.

38. Barrett S, Bartlett S, Bolt A, Ironmonger A, Joce C (2005) Configurational stability of bisindolylmaleimide cyclophanes: from conformers to the first configurationally stable, atropisomeric bisindolylmaleimides. Chemistry 11(21): 6277-6285.

39. Hanahan D, Weinberg RA (2000) The hallmarks of cancer. Cell 100(1): 57-70.

40. Secchiero P, Zauli G (2008) Tumor-necrosis-factor-related apoptosisinducing ligand and the regulation of hematopoiesis. Current Opinion in Hematology 15(1): 42-48. 
41. Yonezawa T, Kurata R, Kimura M, Inoko H (2009) PKC delta and epsilon in drug targeting and therapeutics. Recent Patents on DNA \& Gene Sequences 3(2): 96-101.

42. Arnize (2014) Personal Communication referring to his own experiment

43. Beck WT, Morgan SE, Mo YY, Bhat UG (1999) Tumor cell resistance to DNA topoisomerase II inhibitors: new developments. Drug Resistance Updates 2(6): 382-389.

44. Boland MP, Fitzgerald KA, O Neill LA (2000) Topoisomerase II is required for mitoxantrone to signal nuclear factor kappa B activation in HL60 cells. The Journal of Biological Chemistry 275(33): 25231-25238.

45. Breitman TR, Collins SJ, Keene BR (1980) Replacement of serum by insulin and transferrin supports growth and differentiation of the human promyelocytic cell line, HL-60. Experimental Cell Research 126(2): 494-498

46. Jaiswal S, Jamieson CH, Pang WW, Park CY, Chao MP, et al. (2009) CD47 is upregulated on circulating hematopoietic stem cells and leukemia cells to avoid phagocytosis. Cell 138(2): 271-285.
47. Li L, Neaves WB (2006) Normal stem cells and cancer stem cells: the niche matters. Cancer Research 66(9): 4553-4557.

48. Minotti G, Menna P, Salvatorelli E, Cairo G, Gianni L (2004) Anthracyclines: molecular advances and pharmacologic developments in antitumor activity and cardiotoxicity. Pharmacological Reviews 56(2): 185-229.

49. Sivaprasad U, Shankar E, Basu A (2007) Downregulation of Bid is associated with PKCepsilon-mediated TRAIL resistance. Cell Death and Differentiation 14(4): 851-860.

50. Wasowska M, Wietrzyk J, Opolski A, Oszczapowicz J, Oszczapowicz (2006) Effect of structural modifications of anthracyclines on the ability to overcome drug resistance of cancer cells. Anticancer Research 26(3A): 2009-2012.

51. Wasowska Lukawska M, Wietrzyk J, Opolski A, Oszczapowicz J, Oszczapowicz I (2007) Biological properties of new derivatives of daunorubicin. In Vivo 21(2): 413-416.

52. Zhou SF (2008) Structure, function and regulation of P-glycoprotein and its clinical relevance in drug disposition. Xenobiotica 38(7-8): 802-832. 